\title{
Disaster Making in the Capitalocene
}

\author{
Global Environmental Politics - Forum piece
}

Accepted 19 November 2021

\section{Authors}

Shannon O'Lear

Francis Masse

Hannah Dickinson

Rosaleen Duffy

\section{Acknowledgement}

This project was made possible with support from a European Research Council grant for the BIOSEC Project, number 694995

\footnotetext{
Abstract

We live in a new normal of increasing, cross-cutting and shifting patterns of disasters fuelled by large scale environmental change, from floods to wildfires to pandemics. Our intervention in this forum piece makes the case that disasters, and responses to disasters, must be understood within the context of the global political economic system of capitalism. We situate disasters, their making, and their politics within the Capitalocene and argue that disasters and the physical processes that underpin them are not natural: they are unevenly produced through, and exacerbated by, processes inherent in the capitalist system with uneven consequences. We suggest that the predominantly techno-managerial approaches to disasters pursued within the neoliberal state and multilateral governance institution system reveal the tensions in addressing the causes of environmental change and the new normal of disasters under Capitalism. We argue that through an engagement with the Capitalocene, environmental politics could further contribute to nuanced, critical understandings of disasters and their making that in ways that foreground their in/justice implications.
}

\section{Introduction}

This short forum piece focuses on situating disasters, and specifically their making, within the Capitalocene. We live in a new normal of increasing, cross-cutting and shifting patterns of disasters, from floods to wildfires to pandemics, fuelled by large scale environmental change. There is considerable 
scholarship across disciplines focused on analysing, predicting, and developing responses to disasters of many types. Our intervention here argues that disasters, their making, and related politics must be understood within the context of the global political economic system of capitalism that underpins processes of environmental change, as well as the ways in which they are governed and addressed. We suggest that a useful lens through which we can understand these dynamics of disaster is 'The Capitalocene' (Moore 2015). While it is now common to eschew any understanding of disasters as 'natural' given how the destruction and loss associated with hazards like floods, fires and drought are socio-political outcomes, we extend this logic further by foregrounding the political-economic dimensions that shape the biophysical processes of environmental change. Taking the Capitalocene seriously accounts for the ways in which the biophysical processes underlying/precipitating hazards and disasters are themselves no longer natural. They are unevenly produced through, and exacerbated by, processes inherent in the capitalist system with uneven consequences. This is what we refer to as disaster-making in the Capitalocene. This shift in focus matters for environmental politics, because it could create an opportunity for intervention rather than after-the-fact response.

The Capitalocene framework complements critical work in international political economy of the environment (IPEE) by examining the political dimensions of the uneven costs and benefits resulting from how nature and its governance are organized and deeply altered through capitalist systems of production and consumption (Newell \& Lane 2017; Paterson 2000; Saurin 2001; Sovacool \& Linnér 2016). In line with the emerging recognition of Capitalocene thinking in the social sciences, we argue here that the framework of the Capitalocene could be further integrated into the broader discipline of global environmental politics, and specifically critical work on disasters, in productive ways. While Capitalism is by no means the only political-economic system that has wrought environmental damage, several analyses connect the rapidly proliferating Anthropogenic environmental change that underpins our new normal to the equally rapid development of global capitalism (especially industrial capitalism), as a way of organizing production, consumption and, importantly, nature (Moore, 2015; Kallis and Sager, 2016; Malm, 2020). Hence, scholars invoke the term Capitalocene, rather than Anthropocene, to make sense of the current era of global environmental change. Unlike the Anthropocene, the Capitalocene necessarily extends to the dominance and functioning of the neoliberal state and multilateral governance institution system, which works to manage human-environment relations within a global capitalist framework (Moore, 2015; Wainwright and Mann, 2018). More specifically, we suggest that the predominantly techno-managerial approaches to disasters pursued within this system reveal the tensions in addressing the causes of environmental change and the new normal of environmental change and disasters under Capitalism. We argue that through an engagement with the Capitalocene, environmental 
politics could further contribute to nuanced, critical understandings of disasters and their making that in ways that foreground their in/justice implications.

\section{Disasters in the practice and scholarship of global environmental politics}

The underlying processes of disaster making are largely overlooked by dominant systems and thinking on the politics of disasters. For example, the international frameworks to address and govern disasters, The Sendai Framework for Disaster Risk Reduction (2015-2030) focuses largely, although not exclusively, on assessing and mitigating disaster risk by improving disaster preparedness and resilience measures. While mentioning the exacerbating effects of climate change and rightly seeking to build resilience and improve information systems to adapt to the growing threats it poses and to reduce socio-economic and material vulnerabilities, the framework does not address adequately the structural or systemic causes of the hazards or disaster processes, such as the burning of fossil fuels driving anthropogenic climate change and industrial processes of land-use change. Rather, it offers a primarily techno-managerial approach to mitigating and managing the impacts of disasters and subsequent socio-economic and material losses (de la Poterie \& Baudoin, 2015).

Much work on disasters in politics and international relations (IR) similarly looks to institutional and techno-managerial approaches to increase resilience and adaptive capacity of governments and governance systems (Rajão \& Georgiadou 2014; Gillard 2016; Chu 2018; Ferguson 2019). There is an explicit acceptance within this framework that climate change will lead to more frequent and more complex disasters. While adaptation is certainly necessary, the framework is apolitical, and implicitly accepts working within and adapting to this political-economic-ecological and governance reality, and thereby "skirt over questions of causality and responsibility" (Vanhala \& Hestbaek 2016, 125). Whilst acknowledging the damaging tendencies of capital and the current global political-economic system, certain approaches to environmental governance in political science, like Earth Systems Governance (Biermann 2014; Galaz 2014) and Planet Politics (Burke et al. 2016) are subject to similar critiques (Swyngedouw 2013; Lövbrand et al. 2015; Wainwright and Mann 2018; Albert 2020).

Traditional, realist approaches and more liberal approaches reinforce existing governance structures and systems by framing environmental concerns in ways that tend to be addressed through those very same structures and systems (Albert 2020). International governance systems currently distinguish between frameworks on disaster risk reduction, like the Sendai Framework, and those frameworks or conventions addressing the underlying causes of increasing 'natural' hazards or biophysical processes leading to disasters, such as the United Nations Framework Convention on Climate Change (UNFCCC) (Vanhala \& 
Hestbaek, 2016). The separation of the governance of disasters and underlying processes of disastermaking reflects existing systems, structures, and thinking that are failing. Indeed, the system of sovereign states and the dominant, technological response to environmental disasters is inadequate to respond to or even understand cascading disasters (Park 2021). Unlike scholarship on disaster capitalism which examines shifting responsibility for security and the commodification of disaster (Lawrence and Wiebe 2017), we are interested in the role of the capitalist system in setting the biophysical stage for disasters to unfold and intersect. We suggest the Capitalocene provides a critical starting point for understanding human-environmental disasters, from climate change impacts to zoonotic pandemics, that can further invigorate scholarship on the global environmental politics of disaster making by centering how global processes of capitalism are part and parcel not only of disaster-making, but of shaping mainstream responses that fail to address disasters' underlying causes. It will be essential in these efforts to overcome (or undermine) modern governance systems that do not operate with a cosmopolitan comprehension of the inherently integrated and uncertain aspects of disasters (Selchow 2021).

\section{Anthropocene: Useful, but not far enough}

The Anthropocene acknowledges that human activity since the industrial revolution and the widespread practice of using nitrogen-based fertilizers has effectively shifted the planet into a new geological era in which we cannot separate human activity from an idealized, external environment (if we ever could) (Crutzen and Stoermer 2000). However, critics argue that work in IR and global environmental politics scholarship has not sufficiently engaged with the Anthropocene (see for e.g. Simangan 2020). Newell and Lane (2017) further argue that we need a more critical IPEE to address the challenges of the Anthropocene, recognizing that productive Anthropocene-related thinking has happened outside of IPEE. For example, Geographer Susan Cutter (2020) argues that the new normal and changing nature of disaster risk and hazards in the Anthropocene is characterized by more mundane, every day, chronic and cascading events with effects that stretch over space and time, often far away from a large disaster event and often intersecting with increasingly unequal distribution of disaster risk.. Anthropocene thinking thus considers the ways that human-induced alterations to social and natural systems have emergent impacts on each other, and considers what these interactions mean for disasters.

Critics of Anthropocene thinking highlight that the Anthropocene can apolitically present environmental change and human impacts as somehow universal, instead of resulting from highly uneven politicaleconomic and ecological processes that reinforce systems of power, benefit, and (dis)advantage (Castree 2014). Although a fuller consideration of critical perspectives on the Anthropocene is beyond the scope of this short piece, a key critique to mention is that Anthropocene framings are too monolithic to be useful to 
society, polity development, or as an analytical construct (Biermann et al. 2016). There is, argues Scholsberg (2019, p. 54), "an empty space, or even a negative space, in much Anthropocene writing in relation to justice and environmental justice."

A growing body of critical IR and global environmental politics scholarship similarly argues the broader global environmental politics' focus on "treaties, institutions and regimes that are concerned explicitly with the intersection of the economy and the environment" misses and even obscures the structural underpinning of environmental change and its consequences (Newell \& Lane 2017, 137; Saurin 2001; Wapner 2014; Brondizio et al. 2016; Pattberg \& Zelli 2016; Inoue 2018; Whetung 2019). The Capitalocene moves responsibility for environmental change and harm away from a broad, generalized, undifferentiated category of human activity to the more specific, political-economic system of industrial capitalism.

\section{Capitalocene and the (unjust) organization of nature}

Our intervention builds on this critical IPEE scholarship that engages with aspects of the systemic, structural processes of capital and how they contribute to global environmental change, even if they do not specifically invoke the term Capitalocene (Dalby 2004; Dalby 2020; Newell \& Lane 2017; Albert 2020). Capitalocene, however, adds a specific emphasis to existing IPEE scholarship: "Capitalism is not an economic system; it is not a social system; it is a way of organizing nature" (Moore 2015, 2).

A core contribution of Capitalocene to critical thinking on the politics of disasters and disaster-making that we also see elsewhere in political ecology starts with an understanding of the artificial Nature-Society divide produced under the Capitalocene. Specifically, Capitalism sees and produces Nature as external to Society, and as something to be used and worked through for economic growth and capital accumulation. "If profit was to govern life, a significant intellectual state shift had to occur: a conceptual split between Nature and Society" (Patel and Moore 2018,24). Any thinking on the politics of disasters must start with how nature is organized as (cheaply) separate from society under and for the purposes of Capitalism. The cheapening of Nature, made possible by artificially separating us humans and societies from it and the broader web of ecological life that sustains us, makes Capitalism possible (Patel and Moore 2018). Two processes that result from this separation and cheapening that make Capitalism possible are also utterly destructive, and directly responsible for disaster-making in two ways: 1. destroying our socio-ecological system through unchecked extraction and use of Nature, and 2. negative externalities of industrial capitalism's production and consumption that further harm and re-structure our socio-ecological systems (e.g. CO2 emissions from burning of fossil fuels leading to climate change). Importantly, the naturesociety divide also encourages divisive thinking in other areas such as: which parts of 'nature' should be 
protected or let to die (Biermann and Anderson 2017); scientific categories and rankings that open pathways to harm (Lidstromm et al 2015); and to be clear, divisions between groups of people (Patel and Moore 2018) that, effectively serve as boundaries that shape the distribution and experience of environmental harms, disasters and related (in)justice.

The popular dualism that divides humans from the environment continues to be prevalent in some academic engagement with the Anthropocene, as others have noted (Wapner 2014; Simangan 2020). This is despite the fact that critique of this dualism is foundational to the problematization of environmental politics within global environmental politics itself (Ibid), and in other disciplines, like political ecology and geography, which engage with Capitalocene thinking (Moore 2015; Wainwright and Mann 2018). The normalization of the separation of human and nature poses a challenge for understanding and addressing environmental politics and challenges of disasters (Wapner 2014), as it contributes to obscuring the actual causes of disasters and the 'natural' phenomenon or events that trigger them. Simply put, we cannot separate Capitalism from nature or the biophysical processes tied to disasters, for Capitalism is inherently an ecological project (Moore 2015).

Seeing Capitalism as an ecological system itself is necessary for understanding the unnaturalness of disasters beyond already common understandings of disasters as socio-political, not natural, phenomenon. It is commonly understood, for example, that while certain physical phenomena or hazards like floods, hurricanes, drought and wild fires might be 'natural' phenomena, the negative impacts of these events death, injury, destruction, hunger, human and non-human suffering - are not (Cannon, 1994). This is precisely why drought in Sub-Saharan Africa might be a much larger 'disaster' in terms of human death and suffering than drought in the mid-west of the United States of America. However, much disaster thinking and politics maintains a distinction between biophysical processes (read: hazards), like floods, hurricanes, droughts, wildfire, and their human and non-human or societal impacts, which are inherently social, political and economic.

A politics of disasters and their making in the Capitalocene necessitates a shift in how we understand disasters and their 'natural' hazard triggers. In accepting the premise of the Capitalocene, and even the Anthropocene, it is no longer accurate to refer to or address the 'biophysical' processes of storms, hurricanes, droughts, wildfires, or even zoonotic outbreaks and their severity and increasing frequency as natural processes that have differentiated impacts on people in the form of disasters. Under the Capitalocene, these biophysical processes are socio-natural (Saurin, 2001). They are the product of historic, ongoing processes of systematic, environmental harm, sanctioned by state and multilateral 
governance institutions in ways that have radically re-organized interactions across different spheres of life and the earth's physical processes for the benefit of capital accumulation. This conceptual shift entails a move from understanding the unnaturalness of disasters in terms of long-term structural processes that produce uneven geographies of risk and vulnerability to natural hazards, to the unnaturalness of biophysical processes that precipitate hazards and processes like floods, wildfires, hurricanes and drought themselves. The Capitalocene goes further than the Anthropocene by foregrounding the uneven causalities and distribution of benefits and impacts of the separation of Nature and Society and subsequent environmental changes to focus attention on inequity and injustice, of who wins and who loses (Patel and Moore 2018). Acknowledging the falsity and harm of the Nature-Society divide could also help do away with the separation between disaster governance mechanisms and frameworks and those focused on broader drivers of socio-environmental change, like climate change, for a more integrated approach to politics of disaster mitigation.

\section{Conclusion - A Politics for Disaster-making in the Capitalocene}

In line with critical approaches in IPEE, rather than offering tools and solutions aligned with the same system that generated the problem, Capitalocene thinking recognizes that the systems of production and consumption, as well as governance arrangements, are embedded in a global system of organizing the economy, nature and human-environment relations in ways that further capitalist growth and accumulation. Additionally, this framework emphasizes that these systems and governance structures are in fact contributing factors to the frequency, severity, and complex nature of contemporary disasters. Integrating a Capitalocene perspective to existing debates in global environmental politics opens the possibility to further question existing dominant systems and address them as foundational to and complicit in the socio-ecological crises and disasters we face. Re-framing disasters and their politics in the framework of the Capitalocene brings to the fore the socio-political-economic-ecological processes of environmental change and altered biophysical processes - disaster-making - that any politics of disasters must account for, engage with, and work to disrupt. We propose this work as one potential step towards more critical thinking on the political, social and economic transformation that is required for structural change to address environmental change that underpins disasters and their making, paying necessary attention to the injustices that characterize our current socio-economic-political systems. 


\section{Author Bios}

Shannon O'Lear

Professor Shannon O’Lear is a political geographer in the Department of Geography \& Atmospheric Science and the Director of the Environmental Studies Program at the University of Kansas. Her recent publications include A Research Agenda for Geographies of Slow Violence: Making Social and Environmental Injustice Visible (Edward Elgar 2021); Environmental Change and Human Security Research Directions for the National Science Foundation A Report of the NSF Advisory Committee for Environmental Research and Education (2021), https://www.nsf.gov/ere/ereweb/reports/AC-ERE-Environmental-Security-Report 508.pdf; and "Environmental geopolitics of climate engineering proposals in the IPCC 5th Assessment Report”, Frontiers in Climate (Research Topic: Security Politics, Risk and Climate Geoengineering), https://www.frontiersin.org/articles/10.3389/fclim.2021.718553/abstract.

Francis Masse

Francis Masse is a human-environment geographer and political ecologist. He is a Senior Lecturer in the Department of Geography and Environmental Sciences at Northumbria.

\section{Hannah Dickinson}

Hannah Dickinson is a postdoctoral research associate working in the department of Geography at Durham University, UK. Her work draws upon approaches in political ecology, critical geopolitics and political geography to think about the intersections of environmental governance, biodiversity conservation and international trade in marine species and their derivatives. Hannah's current research on shrimp-derived chitosan contributes to the Leverhulme funded 'Circulatory Entanglements' project, which explores how marine organisms and their biomaterials circulate through different policy, economic, and scientific contexts as part of Blue Economy initiatives that tie human and ocean health together.

\section{Rosaleen Duffy}

Professor Rosaleen Duffy is a political ecologist whose research centres on the international politics of conservation. She held an ERC grant (2016-2020) for the BIOSEC Project and is currently Principal Investigator on the ESRC funded Beastly Business Project (2021-2023) on 
political ecologies of green collar crime, examining the illegal trade in European wildlife. She is author of a forthcoming book on Security and Biodiversity (Yale University Press 2022).

\section{Works Cited}

Albert, Michael J. 2020. Capitalism and Earth System Governance: An Ecological Marxist Approach. Global Environmental Politics 20 (2): 37-56.

Biermann, Christine, and Robert M. Anderson. 2017. Conservation, Biopolitics, and the Governance of Life and Death. Geography Compass 11 (10): e12329.

Biermann, Frank. 2014. Earth System Governance: World politics in the Anthropocene. Cambridge, MA: MIT Press.

Biermann, Maureen, Kevin C. Hillmer-Pegram, Corrine Noel Knapp, and Richard E. Hum. 2016. Approaching a Critical Turn? A Content Analysis of the Politics of Resilience in Key Bodies of Resilience Literature. Resilience 4 (2): 59-78.

Brondizio, Eduardo S., Karen O’Brien, Xuemei Bai, Frank Biermann, Will Steffen, Fans Berkhout, Christophe Cudennec, Maria Carmen Lemos, Alexander Wolfe, Jose PalmaOliveira, Chen-Tung Arthur Chen. 2016. Re-conceptualizing the Anthropocene: A Call for Collaboration. Global Environmental Change 39: 318-327.

Burke, Anthony, Stefanie Fishel, Audra Mitchell, Simon Dalby, and Daniel J. Levine. 2016. Planet politics: A Manifesto From the End of IR. Millennium 44 (3): 499-523.

Cannon, Terry. 1994. Vulnerability Analysis and Explanation of 'Natural' Disasters. In Disasters, Development and Environment, edited by Ann Varley, 13-30. New York, NY: John Wiley \& Sons Ltd.

Castree, Noel. 2014. The Anthropocene and Geography I: The Back Story. Geography Compass 8 (7): 436-449.

Chu, Eric K. 2018. Transnational Support for Urban Climate Adaptation: Emerging Forms of Agency and Dependency. Global Environmental Politics 18 (3): 25-46. 
Crutzen, Paul J., and Eugene F. Stoermer. 2000. The Anthropocene. International GeosphereBiosphere Programme (IGBP) Global Change Newsletter 41 (May): 17-18.

Cutter, Susan L. 2020. The Changing Nature of Hazard and Disaster Risk in the Anthropocene. Available at: https://doi.org/10.1080/24694452.2020.1744423, last accessed September 3, 2020. (Annals of the American Association of Geographers 1-9.)

Dalby, Simon. 2004. Ecological Politics, Violence, and the Theme of Empire. Global Environmental Politics 4 (2): 1-11.

Dalby, Simon. 2020. Anthropocene Geopolitics: Globalization, Security, Sustainability. Ottawa, ONT: University of Ottawa Press.

Davies, Thom. Forthcoming 2021. Geography, Time, and Environmental Justice: Slow Observation in Louisiana, In A Research Agenda for Geographies of Slow Violence, edited by [Author]. Cheltenham, UK: Edward Elgar Publishing.

de la Poterie, Arielle Tozier, and Marie-Ange Baudoin. 2015. From Yokohama to Sendai: Approaches to Participation in International Disaster Risk Reduction Frameworks. International Journal of Disaster Risk Science 6 (2): 128-139.

Ferguson, Peter. 2019. Discourses of Resilience in the Climate Security Debate. Global Environmental Politics 19 (2): 104-126.

Galaz, Victor, ed. 2014. Global Environmental Governance, Technology and Politics: The Anthropocene Gap. Cheltenham, UK: Edward Elgar Publishing.

Gillard, Ross. 2016. Questioning the Diffusion of Resilience Discourses in Pursuit of Transformational Change. Global Environmental Politics 16 (1): 13-20.

Inoue, Cristina Yumie Aoki. 2018. Worlding the Study of Global Environmental Politics in the Anthropocene: Indigenous Voices from the Amazon. Global Environmental Politics 18 (4): $25-42$.

Kallis G., Sager J. 2016. Oil and the Economy: A Systematic Review of the Literature for Ecological Economists. Ecological Economics 131, 561-571.

Lawrence, Jennifer L. and Sarah Marie Wiebe, eds. 2017. Biopolitical Disaster. Oxfordshire, UK: Taylor \& Francis. 
Lidstrom, Susanna, Simon West, Tania Katzschner, María Isabel Perez-Ramos, Hedley Twidle. 2015. Invasive Narratives and the Inverse of Slow Violence: Alien Species in Science and Society. Environmental Humanities 7 (1): 1-40.

Lövbrand, Eva, Silke Beck, Jason Chilvers, Tim Forsyth, Johan Hedrén, Mike Hulme, Rolf Lidskog, Eleftheria Vasileiadou. 2015. Who Speaks for the Future of Earth? How Critical Social Science Can Extend the Conversation on the Anthropocene. Global Environmental Change 32: 211-218.

Malm, Andreas. 2020. Corona, Climate, Chronic Emergency: War Communism in the Twenty-First Century. London, UK: Verso.

Moore, Jason W. 2015. Capitalism in the Web of Life: Ecology and the Accumulation of Capital. New York, NY: Verso Books.

Newell, Peter, and Richard Lane. 2017. IPE and the Environment in the Age of the Anthropocene. In Traditions and Trends in Global Environmental Politics, edited by Olaf Corry and Hayley Stevenson, 136-153. Abingdon, UK: Routledge.

O’Lear, Shannon. 2018. Environmental Geopolitics. Boulder, CO: Rowman \& Littlefield.

Park, Susan. 2021. The Role of the Sovereign State in 21st Century Environmental Disasters. Environmental Politics. Published online 23 Feb., pp. 1-20. DOI:

$10.1080 / 09644016.2021 .1892983$

Paterson, Matthew. 2000. Understanding Global Environmental Politics: Domination, Accumulation, Resistance. Berlin, Germany: Springer.

Pattberg, Philipp, and Fariborz Zelli. 2016. Global Environmental Governance in the Anthropocene: An Introduction. In Environmental Politics and Governance in the Anthropocene (pp. 15-26): Routledge.

Rajão, Raoni, and Yola Georgiadou. 2014. Blame Games in the Amazon: Environmental Crises and the Emergence of a Transparency Regime in Brazil. Global Environmental Politics 14 (4): 97-115.

Saurin, Julian. 2001. Global Environmental Crisis as the 'Disaster Triumphant': The Private Capture of Public Goods. Environmental Politics 10 (4): 63-84. 
Schlosberg, David. 2019. Disruption, Community, and Resilient Governance: Environmental Justice in the Anthropocene. In The Commons in a Global World: Global Connections and Local Responses, edited by Tobias Haller, Thomas Breu, Tine De Moor, Christian Rohr, and Heinzpetere Znoj, 54-71. London, UK: Routledge.

Selchow, Sabine. 2021. Planetary Disasters: Moving the UN Disaster Risk Reduction Framework into Cosmopolised Reality. Environmental Politics. Published online 4 Jan., pp. 1-21. https://doi.org/10.1080/09644016.2020.1868819

Simangan, Dahlia. 2020. Where is the Anthropocene? IR in a New Geological Epoch. International Affairs 96 (1): 211-224.

Sovacool, Benjamin K., and Björn-Ola Linnér. 2016. The Political Economy of Climate Change Adaptation: Berlin, Germany: Springer.

Swyngedouw, Erik. 2013. The Non-political Politics of Climate Change. ACME: An International Journal for Critical Geographies 12 (1): 1-8.

Vanhala, Lisa, and Cecilie Hestbaek. 2016. Framing Climate Change Loss and Damage in UNFCCC Negotiations. Global Environmental Politics 16 (4): 111-129.

Wainwright, Joel, Geoff Mann. 2018. Climate Leviathan: A Political Theory of our Planetary Future. New York, NY: Verso Books.

Wapner, Paul. 2014. The Changing Nature of Nature: Environmental Politics in the Anthropocene. Global Environmental Politics 14 (4): 36-54.

Whetung, Madeline. 2019. (En)gendering Shoreline Law: Nishnaabeg Relational Politics Along the Trent Severn Waterway. Global Environmental Politics 19 (3): 16-32. 